\title{
Despoblamiento y turismo en zonas de baja densidad: otra perspectiva sobre el efecto del turismo en el patrimonio
}

\author{
Ana Costa Rosado | doctoranda en arquitectura en la Universidad de Sevilla y en el Campo Arqueológico de Mértola \\ Miguel Reimão Costa | Facultade de Ciencias e Tecnología, Universidade do Algarve \\ María Teresa Pérez Cano | Dpto. de Urbanística y Ordenación del Territorio, Universidad de Sevilla \\ URL de la contribución <www.iaph.es/revistaph/index.php/revistaph/article/view/4481>
}

El debate sobre conservación y transformación del paisaje histórico urbano se centra, en los últimos años, en los problemas emanados de la masificación del turismo -no sólo los criterios de conservación del patrimonio construido, también las alteraciones profundas en los tejidos sociales-, sobre todo en zonas de fuerte dinamismo económico. Sin embargo, la mayoría de los territorios de baja densidad en el interior de la Península se enfrentan a una serie de problemas antagónicos a la masificación, relacionados más bien con el abandono poblacional y la consecuente degradación de sus estructuras físicas. En ciudades de media y pequeña dimensión, los problemas de conservación y valoración del patrimonio local, construido y cultural, pasan por la falta de condiciones económicas para la retención de población. El progresivo despoblamiento es la causa del cada vez mayor envejecimiento poblacional, del abandono del edificado habitacional y, consecuentemente, de otras estructuras patrimoniales. La pregunta "¿Qué consecuencias sobre el patrimonio cultural tiene la desaparición de comunidad?" se debe contrarrestar con ¿Cómo puede el patrimonio ser un instrumento de desarrollo para estas comunidades, que ayude a conservar a sus habitantes y el significado de los sitios?

En los territorios de baja densidad, los centros históricos de las ciudades están hoy bajo una curiosa condición, muy distinta a la de grandes urbes: la de doblemente periféricos. Desde hace décadas, los habitantes de estos barrios frecuentemente amurallados y de difícil acceso se han desplazado hacia nuevas urbanizaciones adaptadas al uso del automóvil. El vaciamiento del centro lleva a la pérdida de su función y significado dentro de las relaciones orgánicas de la ciudad. Consecuentemente, se transforma en un lugar periférico, por donde nadie pasa. Un lugar periférico dentro de ciudades también periféricas a escalas regionales/nacionales, muchas veces ignoradas en la toma de decisiones. Cuanto menor es el número de habitantes, menos servicios son albergados y menor será la probabilidad de atraer y fijar nuevos residentes. Nace un estigma de pobreza y precariedad asociado al tejido urbano histórico.

Aun así, esta condición de doble-periferia puede significar, con distinta probabilidad, tanto un factor de desaparición como una oportunidad de conservación patrimonial. El abandono de los centros históricos ha conllevado degradación física que puede significar la desaparición del edificado. Así, es de carácter urgente su documentación y estudio, al igual que el debate sobre la importancia de este legado, hoy discutido bajo la dicotomía desertificación/turistificación. Pero el mismo abandono que crea riesgo de colapso ha contribuido a la menor transformación de los conjuntos y la permanencia de tipologías resultantes del proceso histórico. Con baja presión de transformación, los centros históricos han mantenido sus formas y espacialidades. En muchos casos, no han sido distorsionados por interpretaciones pseudo-históricas de la realidad tradicional y por eso constituyen una oportunidad para estudiar, analizar y crear estrategias de conservación para urbes seculares. Sin embargo, la conversión del patrimonio en un recurso socio-económico requiere más que su estudio. Como indica el Memorando de Viena (VIENNA, 2005), el paisaje urbano histórico debe promover oportunidades socio-económicas mientras se preserva el entorno patrimonial. El turismo aún es percibido en las urbes de pequeña y mediana dimensión como la mejor forma de crear pues- 
tos de trabajo y retener población joven. La valorización patrimonial es en estos casos una importante herramienta contra los estigmas de pobreza y degradación, ya que, al valorar la comunidad residente y sus estructuras, refuerzan la identidad cultural de los lugares.

El deterioro de las condiciones de habitabilidad de los barrios históricos también está relacionado con la baja participación popular en la discusión cívica/política, por ausencia o avanzada edad de sus vecinos. Un fuerte sentido de comunidad, apoyado en sentimientos de orgullo y de pertenencia-que pueden ser generados por políticas de valoración patrimonial-, ayuda a que los residentes sean partícipes de la toma de decisiones. Promover el patrimonio local a través de su estudio y musealización puede ser un instrumento de desarrollo en zonas de baja densidad, si acompañado de cerca por la transmisión de conocimiento a la comunidad, con acciones de divulgación y creación de empleo directamente relacionadas con el patrimonio cultural. En general, la valoración patrimonial debe advenir de investigaciones científicas rigurosas y fuertemente enlazadas con la sociedad civil local. Sólo así puede ser un factor de atracción externa mientras contribuye al desarrollo local y la cohesión social. La producción de conocimiento y su transmisión también puede generar ingresos mientras une la comunidad local. Incluso en el ámbito del turismo, la promoción de valores patrimoniales anclados en investigación científica atrae a un tipo de turista más exigente, ayudando a contener el riesgo de masificación.

Los centros históricos tienen necesidades distintas dependiendo de su tamaño, población, contexto cultural, acceso o demanda turística. Así, la aplicación de políticas patrimoniales genéricas, que no consideren desigualdades territoriales -como la dicotomía litoral/ interior- se traducen en una disparidad de resultados. De esto son ejemplo políticas de turismo, como la limitación del número de licencias de alojamientos turísticos, que muestran resultados muy positivos en ciudades monumentales o costeras saturadas pero generan efectos perniciosos en pequeñas y medias urbes del interior. Las disposiciones generales deben asegurar espacio para aplicación de políticas diferenciadas, adaptadas a la realidad social, económica, cultural o arquitectónica de los conjuntos, para evitar problemas causados por posturas demasiado generalizadas. Actualmente, en zonas de baja densidad, los flujos de turistas no ponen el riesgo la sostenibilidad del sistema social. Existe la oportunidad de conciliar la conservación y estudio patrimonial con desarrollo económico basado en turismo sin perder el equilibrio socio-cultural. Para eso, las entidades regulatorias deben asumir las desigualdades territoriales y buscar un marco nacional dentro del cual se puedan diferenciar políticas regionales. A pesar del peligro que supone la turistificación, el turismo aún es fundamental en la creación de empleos y promoción de servicios: dos aspectos esenciales en la retención de población. Esa es la mayor necesidad a atender para preservar comunidades activas en las regiones interiores y de baja densidad, manteniendo vivo el significado del paisaje urbano patrimonial.

\section{BIBLIOGRAFÍA}

- AMENDOEIRA, A. P. (1998) Monsaraz: Análise do processo de conservação e transformação urbana no século $X X$. Tese doctoral inédita, Universidade de Évora, 1998

- BIANCHINI, F. (1999) The relationship between cultural resources and urban tourism policies: issues from European debates. En DODD, D.; VAN HEMEL, A. (eds.) Planning Cultural Tourism in Europe: a presentation of theories and cases. Amsterdam: Boekman Foundation, 1999, pp. 78-90

- ESPINO HIDALGO, B. (DEL) (2016) Patrimonio, planeamiento y participación: el papel de la ciudadanía en la protección patrimonial local. Revista $\mathrm{PH}$ [en línea], n. ${ }^{\circ}$ 90, 2016, pp. 222-224 <http://www.iaph.es/revistaph/index.php/ revistaph/article/view/3813> [Consulta: 10/07/2019]

- FERRÃo, J. (2010) Governança e ordenamento do território: reflexões para uma governança territorial eficiente, justa e democrática. Prospectiva e planeamento, vol. 170, 2010, pp. 129-139

- VIENNA Memorandum on World Heritage and Contenporary Architecture-Managing the Historical Urban Landscape (2005). Durban: UNESCO, 2005 